\title{
Assessing the role of fungal diversity in decomposition: A meta-analysis.
}

\author{
Sytske M. Drost, Annemieke van der Wal, Wietse de Boer, Paul. L.E. Bodelier
}

\begin{abstract}
Fungi play an important role in carbon - and nutrient cycling. It is, however, unclear if diversity of fungi is essential to fulfill this role. With this meta-analysis, we aim to understand the relationship between fungal diversity and decomposition of plant materials (leaf litter and wood) in terrestrial and aquatic environments. The selection criteria for papers were the presence of a fungal diversity gradient and quantification of decomposition as mass loss. In total 40 papers met the selection criteria. We hypothesized that increase of fungal species will result in stronger decomposition, especially in species poor communities. Both artificial inoculated and naturally assembled fungal communities were included in the analysis in order to assess whether manipulated experiments are representative for field situations. We found a significant positive effect of increased fungal diversity on decomposition. However, in manipulated experiments this relationship was only positive when a control treatment of one fungus was compared with multispecies communities. This relationship became negative when comparisons of higher initial richness (at least two fungal species as "control") were included. In contrast, under natural field conditions increased fungal diversity coincided with increased decomposition. This suggests that manipulated experiments are not representative for field situations. Possible reasons for this are discussed. Yet, both in manipulated and field experiments, environmental factors can influence diversity - decomposition relationships as indicated by a negative relationship of increasing $\mathrm{C}: \mathrm{N}$ ratio on the effect of fungal diversity on decomposition. Overall, our results show that fungal diversity can have an important role in decomposition, but that design of experiments (manipulated or field) and quality of the plant material should be taken into account for interpretation of this diversity-functioning relationship.
\end{abstract}

\section{Introduction}

Understanding the consequences of decreasing biodiversity on the functioning of natural ecosystems is one of the highest research priorities in ecological research (Coleman and Whitman, 2005; Lecerf and Richardson, 2010; Delgado-Baquerizo et al., 2017). An important aspect of the biodiversityfunctioning relationship is the role of belowground biodiversity on soil functioning such as carbon- and nutrient cycling (Wagg et al., 2014; Delgado-Baquerizo et al., 2016). Saprotrophic fungi are an important group of soil microorganisms involved in decomposition of organic materials and mineral nutrient cycling (van der Wal et al., 2013). It is estimated that 1.5 million fungal species occur worldwide (Hyde et al., 2007). They are abundantly present in (undisturbed) ecosystems like grasslands and forest floors, but also in aquatic systems like streams that receive input of terrestrial organic matter (Grossart et al., 2019). Due to their hyphal growth form and ability to produce a wide range of polymer hydrolyzing and -oxidizing enzymes, saprotrophic fungi have a key role in the degradation of solid, lignocellulose-rich organic materials (van der Wal et al., 2013). The number of fungal species with a predominant saprotrophic lifestyle is tremendous and there are strong differences in their abilities to degrade organic compounds (van der Wal et al., 2013). Yet, the importance of this high taxonomical and functional diversity of saprotrophic fungi for decomposition processes is not well understood.

Diversity-functioning relationships are mostly studied in experimental settings after the inoculation of a limited number of fungal isolates on sterile plant residues. Many of these studies have been executed in aquatic experimental settings with terrestrial leaf litter that under field conditions naturally falls into streams (Duarte et al., 2006; Pascoal et al., 2010; Andrade, Pascoal and Cássio, 2016). Manipulated diversity studies in terrestrial ecosystems are less common and do often involve woody materials (Toljander et al., 2006; Wagg et al., 2014; Hiscox et al., 2016). The diversity gradients range from 1 to a maximum of 16 species, which is a common amount of cultivated fungal species retrieved from aquatic ecosystems (Duarte et al., 2010). However, in terrestrial ecosystems much higher diversity 
levels are found (Deacon et al., 2006) and with sequencing techniques even more species are detected, but their function and activity are not yet known (Grossart et al., 2019).

Interactions between fungi are an important aspect to be included in the prediction of the effect of increasing diversity on ecosystem functioning. Fungi can compete for the same resources leading to competitive exclusion. This can lead to a reduction of the initial inoculated diversity levels at the end of experiments (Toljander et al., 2006). In wood logs, competitive interactions are visible between wood-rot fungi (zones between fungal species as described by van der Wal et al. (2013)). When interactions are neutral, fungal species co-occur in the same environment without exhibiting harmful or beneficial effects. Decomposition rates are not expected to be different from the average decomposition of each fungus in monoculture (additive effect). Complementarity and facilitation can lead to increased decomposition. For example, Tiunov and Scheu (2005) showed a positive effect by combining cellulolytic fungi and sugar fungi. The production of cellulase supported the consumption of the released sugars by sugar fungi.

Another aspect that can influence the diversity-decomposition relationship is the chemical composition of the material that is decomposed. Fungal species are adapted to the specific composition of the organic materials they decompose. For example, to overcome lignin barriers in complex organic substrates, degradation (white rot fungi) or modification (brown rot fungi) strategies have been evolved in wood decomposition (Mester, Varela and Tien, 2004). Nutrient availability, lignin content and toxic elements can influence wood and litter decomposition as well as the success and outcome of interactions of fungal species during decomposition.

In general, even though interaction effects can have different directions, it is assumed that diversity is important for decomposition (Baerlocher, 2005; Gessner et al., 2010; Hättenschwiler, Fromin and Barantal, 2011). Yet, there is still a debate on the extent of diversity importance as redundancy effects within the community may occur, since many species are able to break down organic matter. We performed a meta-analysis to better understand the relationship between fungal diversity and decomposition. We screened manipulated diversity studies from both aquatic and terrestrial ecosystems including leaf and woody materials. The selection criteria for papers were 1) the presence of an initial fungal diversity gradient and 2) quantification of decomposition as mass loss. Decomposition measured as $\mathrm{CO}_{2}$ emissions were not included as fungal interactions can affect carbon substrate use efficiencies of individual fungal species leading to difficulties with interpretation of the relationship between respiration and decomposition (Hiscox et al., 2015). The following hypotheses were tested:

1. Diversity increases decomposition as increasing species diversity will lead to increased potential of the community to degrade diverse material (niche differentiation/complementarity).

2. The diversity effect will be flattened off with increasing species richness (redundancy effect with increasing species richness).

3. The diversity effect is expected to be higher in litter or woody materials with lower $\mathrm{C}: \mathrm{N}$ ratio as substrates with a higher $\mathrm{C}: \mathrm{N}$ ratio are more difficult to degrade and will require specialized fungi. These fungi have to invest a lot of energy in their specialization (e.g. lignolytic enzymes) and prevent competition from other microbes by creating unfavorable growth conditions (Boddy and Hiscox, 2016), resulting in decreased fungal diversity in substrates with a high $\mathrm{C}: \mathrm{N}$ ratio.

4. The diversity effect will be reduced when measuring mass loss at later time points as compared to earlier time points within the same substrate; facilitation/complementarity is expected to have larger influence during early stages of decomposition as nutrient content is more diverse leading to a possible increased importance of niche differentiation.

Environmental studies that tested decomposition under field conditions were selected as well to understand if the diversity-functioning relationship was different under field conditions with spontaneous developed fungal diversity compared to manipulated fungal diversity in laboratory settings. In these studies, differences in diversity of fungal species are based on differences in natural assembly processes on similar organic starting materials. We therefore additionally hypothesize that: 
5. Fungal diversity effects will be larger in field settings compared to experimental settings especially in fungal rich communities. In field settings, natural colonization processes (no artificial inoculation) and changing environmental conditions will result in an increase in possible niches.

\section{Material and methods}

\section{Literature search:}

The two main criteria for selection of papers on fungal diversity - decomposition relationships were: (1) decomposition is based on mass loss as \% loss of plant material and (2) fungal diversity (richness) differences have been compared (at least 2 levels of fungal diversity per study). Web of Science was used as database for literature search using the following search words: "fungal diversity" AND ("litter decomposition" OR "wood decomposition"). This yielded 142 papers in Web of Science. Papers were included until the $1^{\text {st }}$ of March 2021. Reference lists of the papers were also checked to include articles that were missed by the literature search in Web of Science. We included laboratory experiments with manipulated fungal diversity levels and environmental experiments where the environment created differences in diversity due to differences in colonization processes in replicates or treatments. Studies that were excluded from the analysis compared/examined: (1) contrasting environments or plant residues, (2) decomposition compared between successional stages of the experiment (no diversity differences between treatments but over time), (3) toxicity effects of metals or other harmful compounds. Based on these criteria, we kept 16 manipulated studies and 24 environmental studies. The list of included studies is shown in Table 1.

Data on decomposition and diversity were extracted from the articles using the online tool WebPlotDigitizer. Data related to plant quality and environment were extracted as well. As most studies did not measure the quality of the plant material used in the experiments, the TRY-database (Kattge et al., 2020) was used to get an estimation of the C:N ratio of the plant material.

Treatments with similar diversity levels, but different species composition, were not analyzed separately. Such treatments were pooled before the analysis using the formulas:

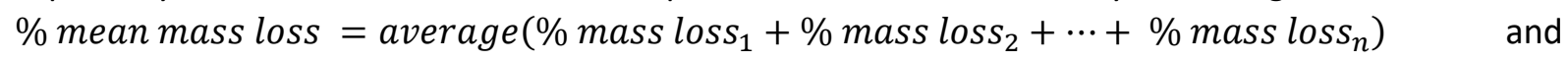
standard deviation $(\sigma)=\operatorname{sum}\left(\sigma_{\% \text { mass }_{\text {loss }}}+\sigma_{\% \text { mass }_{\text {loss }}}+\cdots+\sigma_{\% \text { mass loss }_{n}}\right)^{\frac{1}{n}}$ where $\mathrm{n}$ is the amount of different treatments with the same diversity level. Some environmental papers measured $\mathrm{k}$ decomposition rates and not $\%$ mass loss. These values were calculated into $\%$ mass loss with the formula: \% mass loss $=100 \%-\left(100 \% * e^{-k * t}\right)$ where $\mathrm{k}$ is the decomposition rate and $\mathrm{t}$ is the duration of the incubation (in days or years).

\section{Statistical analyses:}

Data were analyzed with $\mathrm{R}$ (version 4.0.3) with attached packages for analyses and visualization: car, carData, plyr, dplyr, grid, gridExtra, cowplot. The packages metafor and forestplot were used to perform the meta-analysis (Viechtbauer, 2010). Individual effect sizes within each study were estimated by calculating the difference between 2 treatments: $D=$ mass loss $\%_{\text {diverse }}-$ mass loss $\%_{\text {control }}$ and Variance $_{D}=\frac{\sigma^{2} \text { diverse }}{n_{\text {diverse }}}+\frac{\sigma^{2} \text { control }}{n_{\text {control }}}$ where $\mathrm{n}$ is replicates per treatment (diverse or control) (Makowski, Piraux and Brun, 2019). Within each combination, the lowest diversity level was used as "control". All possible combinations in each study were analyzed leading to multiple effect sizes per study when more than two diversity levels were measured. In total 458 combinations obtained from the 40 selected studies were tested. With a random effect model and the REML method overall effect size was estimated. As most studies had more than one individual effect size (D), we corrected for this within the analysis to prevent overestimation of a single study with more 
combinations. To determine differences between experimental design (manipulated or field), environment (aquatic or terrestrial) and plant material (litter or wood), these factors were analyzed separately within the analysis. To analyze redundancy effects, an extra factor was added within the manipulated experiments to compare the individual effect size in measured combinations from real control treatments (1 fungal species) and other treatments with a diverse community already (at least 2 fungal species) as lowest diversity level. A forest plot was made to visualize the individual and overall effect sizes and a funnel plot to estimate publication bias (Sterne and Egger, 2001). Regression analysis (with packages ggplot2, ggpubr) was used to assess whether environmental factors and quality of the plant material could explain the magnitude and direction (positive/negative) of individual effect sizes (ES).

Within the environmental studies, seven studies did not analyze treatments, but individual replicates. To estimate the diversity effect on decomposition, linear regression models were used to estimate $r$ and the variance of the relationship between fungal diversity and \% mass loss. To be able to compare this approach with the group design of all other studies, the regression results were transformed into

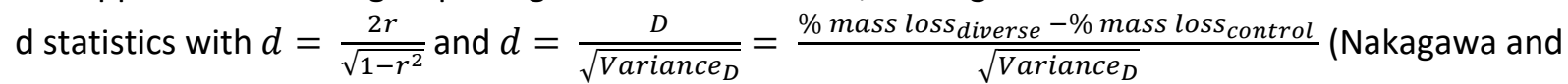
Cuthill 2007) where $r$ is the regression coefficient and $D$ is the estimated difference. These estimates of $D$ were added to the other 33 studies to measure the overall effect as described before.

Table 1: List of papers used in meta-analysis

\begin{tabular}{|c|c|c|c|c|c|}
\hline & Paper & Environment & Plant type & Plant species & Study \\
\hline 1 & Andrade, Pascoal and Cássio (2016) & Aquatic & Litter & Alnus glutinosa & Manipulated \\
\hline 2 & Bärlocher and Corkum (2003) & Aquatic & Litter & Quercus robur & Manipulated \\
\hline 3 & Barros et al. (2016) & Aquatic & Litter & Alnus glutinosa & Manipulated \\
\hline 4 & COSTANTINI and ROSSI (2010) & Aquatic & Litter & $\begin{array}{l}\text { Alnus glutinosa, } \\
\text { Phragmites australis, } \\
\text { Quercus cerris }\end{array}$ & Manipulated \\
\hline 5 & Dang, Chauvet and Gessner (2005) & Aquatic & Litter & $\begin{array}{l}\text { Alnus glutinosa, } \\
\text { Quercus robur }\end{array}$ & Manipulated \\
\hline 6 & Duarte et al. (2006) & Aquatic & Litter & Alnus glutinosa & Manipulated \\
\hline 7 & Fernandes, Pascoal and Cássio (2011) & Aquatic & Litter & Alnus glutinosa & Manipulated \\
\hline 8 & Geraldes, Pascoal and Cássio (2012) & Aquatic & Litter & Alnus glutinosa & Manipulated \\
\hline 9 & Gonçalves, Graça and Canhoto (2015) & Aquatic & Litter & Quercus robur & Manipulated \\
\hline 10 & Jabiol et al. (2013) & Aquatic & Litter & Quercus robur & Manipulated \\
\hline 11 & Kivlin and Treseder (2015) & Terrestrial & Litter & Festuca altaica & Manipulated \\
\hline 12 & Pascoal et al. (2010) & Aquatic & Litter & Tilia cordata & Manipulated \\
\hline 13 & $\begin{array}{l}\text { Raviraja, Nikolcheva and Baerlocher } \\
\text { (2006) }\end{array}$ & Aquatic & Litter & Tilia cordata & Manipulated \\
\hline 14 & Wagg et al. (2014) & Terrestrial & Litter & Lolium multiflorum & Manipulated \\
\hline 15 & Venugopal et al. (2017) & Terrestrial & Wood & Pinus sylvestris & Manipulated \\
\hline 16 & Toljander et al. (2006) & Terrestrial & Wood & Picea abies & Manipulated \\
\hline 17 & Encalada et al. (2010) & Aquatic & Litter & $\begin{array}{l}\text { Alnus acuminate, } \\
\text { Inga spectabilis }\end{array}$ & Field \\
\hline 18 & Ferreira et al. (2006) & Aquatic & Litter & $\begin{array}{l}\text { Alnus glutinosa, } \\
\text { Quercus robur }\end{array}$ & Field \\
\hline 19 & Miura et al. (2013) & Terrestrial & Litter & $\begin{array}{l}\text { Saccharum } \\
\text { officinarum }\end{array}$ & Field \\
\hline 20 & Pascoal, Cassio and Marvanová (2005) & Aquatic & Litter & Alnus glutinosa & Field \\
\hline 21 & Pérez, Descals and Pozo (2012) & Aquatic & Litter & Alnus glutinosa & Field \\
\hline 22 & Maamri et al. (2001) & Aquatic & Litter & Salix pedicellata & Field \\
\hline
\end{tabular}




\begin{tabular}{|l|l|l|l|l|l|}
\hline & Paper & Environment & Plant type & Plant species & Study \\
\hline 23 & Lecerf and Chauvet (2008) & Aquatic & Litter & Alnus glutinosa & Field \\
\hline 24 & Simon, Simon and Benfield (2009) & Aquatic & Litter & Quercus prinus & Field \\
\hline 25 & Tolkkinen et al. (2013) & Aquatic & Litter & Alnus incana & Field \\
\hline 26 & Mikko Tolkkinen et al. (2015) & Aquatic & Litter & Alnus incana & Field \\
\hline 27 & Mesquita, Pascoal and Cassio (2007) & Aquatic & Litter & Eucalyptus globulus & Field \\
\hline 28 & Rincon and Santelloco (2009) & Aquatic & Litter & Ficus & Field \\
\hline 29 & Sudheep and Sridhar (2013) & Aquatic & Litter & $\begin{array}{l}\text { Ficus benghalensis, } \\
\text { Anacardium } \\
\text { occidentale }\end{array}$ & Field \\
\hline 30 & Krevs et al. (2017) & & $\begin{array}{l}\text { Alnus glutinosa, } \\
\text { Alnus negundo }\end{array}$ & Field \\
\hline 31 & Miura et al. (2015) & Aquatic & Litter & $\begin{array}{l}\text { Saccharum } \\
\text { officinarum }\end{array}$ & Field \\
\hline 32 & Hoppe et al. (2016) & Terrestrial & Litter & Picea abies & Field \\
\hline 33 & $\begin{array}{l}\text { Kubartová, Ottosson and Stenlid } \\
\text { (2015) }\end{array}$ & Terrestrial & Wood & Picea abies & Field \\
\hline 34 & Harrop, Marks and Watwood (2009) & Aquatic & Litter & $\begin{array}{l}\text { Alnus oblongifolia, } \\
\text { Platanus wrightii }\end{array}$ & Field \\
\hline 35 & M. Tolkkinen et al. (2015) & Aquatic & Litter & Alnus incana & Field \\
\hline 36 & BÄRLOCHER and GRAÇA (2002) & Aquatic & Litter & $\begin{array}{l}\text { Eucalyptus globulus, } \\
\text { Castanea sativa }\end{array}$ & Field \\
\hline 37 & Xiao et al. (2019) & Terrestrial & Wood & Mixture tree species & Field \\
\hline 38 & Purahong et al. (2017) & Terrestrial & Wood & $\begin{array}{l}\text { Schima superba, } \\
\text { Pinus massoniana }\end{array}$ & Field \\
\hline 39 & $\begin{array}{l}\text { van der Wal, Ottoson and De Boer } \\
\text { (2015) }\end{array}$ & Terrestrial & Wood & Larix kaempferi & Field \\
\hline 40 & van der Wal et al. (2016) & Terrestrial & Wood & $\begin{array}{l}\text { Larix kaempferi, } \\
\text { Quercus rubra }\end{array}$ & Field \\
\hline
\end{tabular}

\section{Results}

\section{Diversity effect}

The overall statistical analysis, including all 40 studies, revealed a significant positive effect $(D=$ $1.57 \pm 0.41, p<0.001$ ) of fungal diversity on decomposition (Figure 1 ), supporting hypothesis 1 . The overall effect size was based on individual effect sizes as revealed by a mixed effect model using REML as method $(\mathrm{AIC}=3254.2, \mathrm{QE}=14515.9, \mathrm{p}<0.001$, Table S1). Most of the included studies were performed in aquatic ecosystems and used leaf litter ( 28 studies). Wood decomposition studies were only done in terrestrial ecosystems ( 8 studies). Correlation based diversity effects in field studies ( 7 studies; see M\&M) did not change the outcome of the analysis, thus it was not needed to distinguish these field experiments from the other experiments. In the analysis, ecosystem (aquatic or terrestrial), resource (leaf litter or wood), experiment (manipulated or natural assembly) and comparison (control or diverse) were analyzed separately to identify the influence of these experimental factors. The control/diverse grouping was only used in manipulated experiments as in field experiments a fixed control treatment with only 1 fungus was not present. All examined comparisons were statistically significant in explaining differences in the diversity effects on decomposition (QM $=34.72$ and $p<0.001)$.

In the manipulated experiments, the effect size of increasing diversity was negative $(D=-1.76 \pm 0.56$, $p<0.001$ ) when a low diverse community (at least two fungal species) was compared with a higher 
diversity level, while increasing fungal diversity from one fungus (no diversity) to more fungal species had a positive effect size $(D=2.96 \pm 0.46, p<0.001)$. This indicates a reduced diversity effect with increasing species richness, which is in line with the role of redundancy proposed in hypothesis 2 . In field experiments, increasing diversity was positively related to decomposition ( $D=2.82 \pm 0.78$, $\mathrm{p}<0.001$ ) supporting hypothesis 5 . When considering the individual effect sizes (D) of all studies, no significant correlation was seen with the size of the lowest fungal diversity level (control) within each comparison (Figure $2, p=0.27$ ). This indicates that for field experiments no evidence for a redundancy effect was found.

Resource type had a significant effect as litter decomposition was significantly increased with increasing fungal diversity $(D=1.65 \pm 0.36, p<0.001)$, whereas this was not the case for decomposition of wood $(D=0.32 \pm 1.61, p=0.84)$. However, the amount of studies with data on wood decomposition was low (8 studies).

To estimate if the selected studies had a publication bias towards studies publishing a significant diversity effect, funnel plot analysis was used to estimate missing studies (Figure 3, Table S2). This resulted in an estimation of missing studies only at the right side of the plot (estimated $110 \pm 13.9$ studies missing), indicating that in the included studies there was a publication bias for no or negative effects of fungal diversity on decomposition.

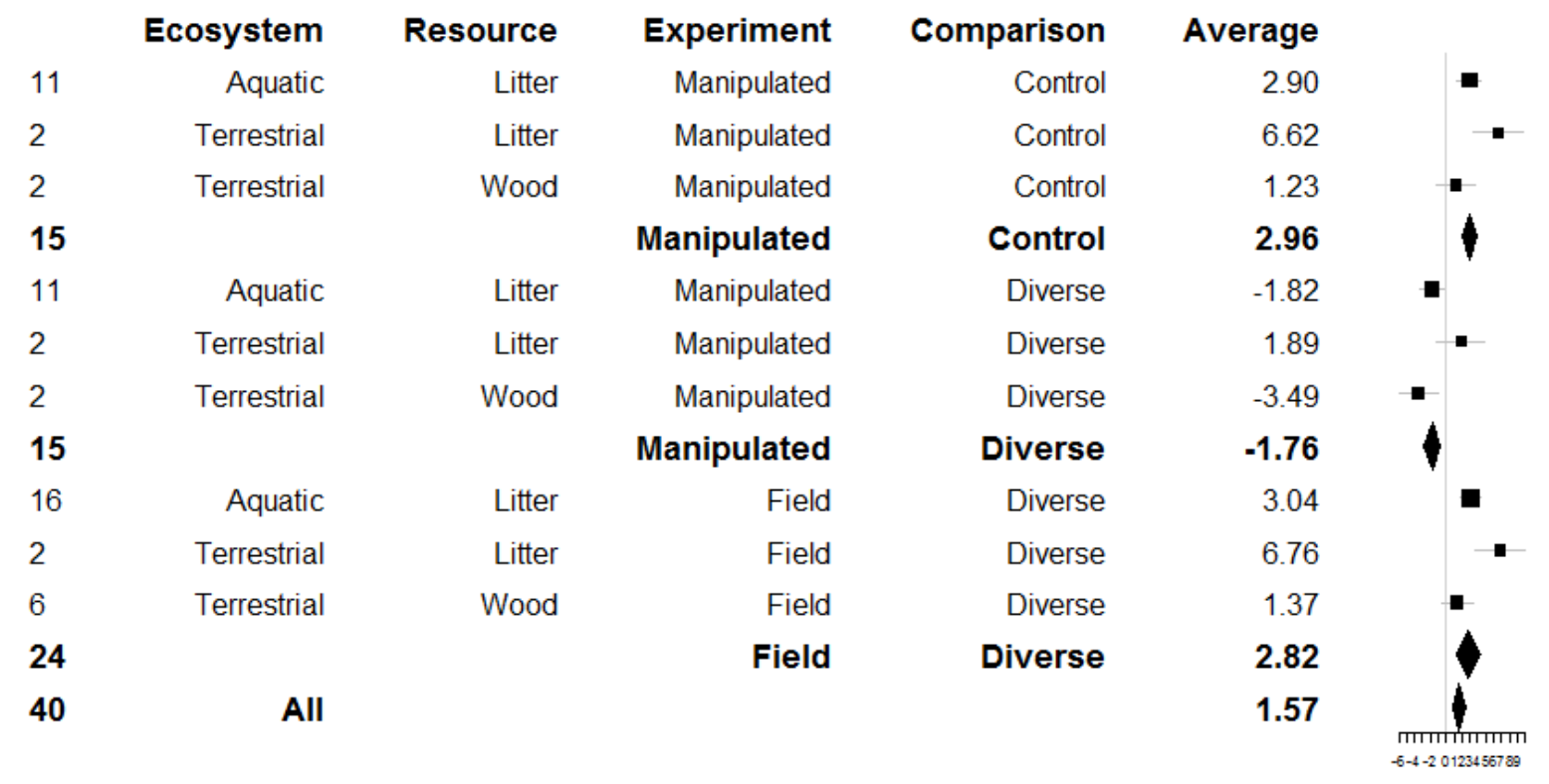

Figure 1: Overall effect size (D) for fungal diversity-decomposition interactions (forest plot), for all studies (All) and different categories within manipulated and field experiments. All data with individual effect sizes of each study calculated as D in forest plot is shown in Figure S1. Numbers in the left column represent the amount of individual studies used in the analysis with a total of 40 papers selected. 


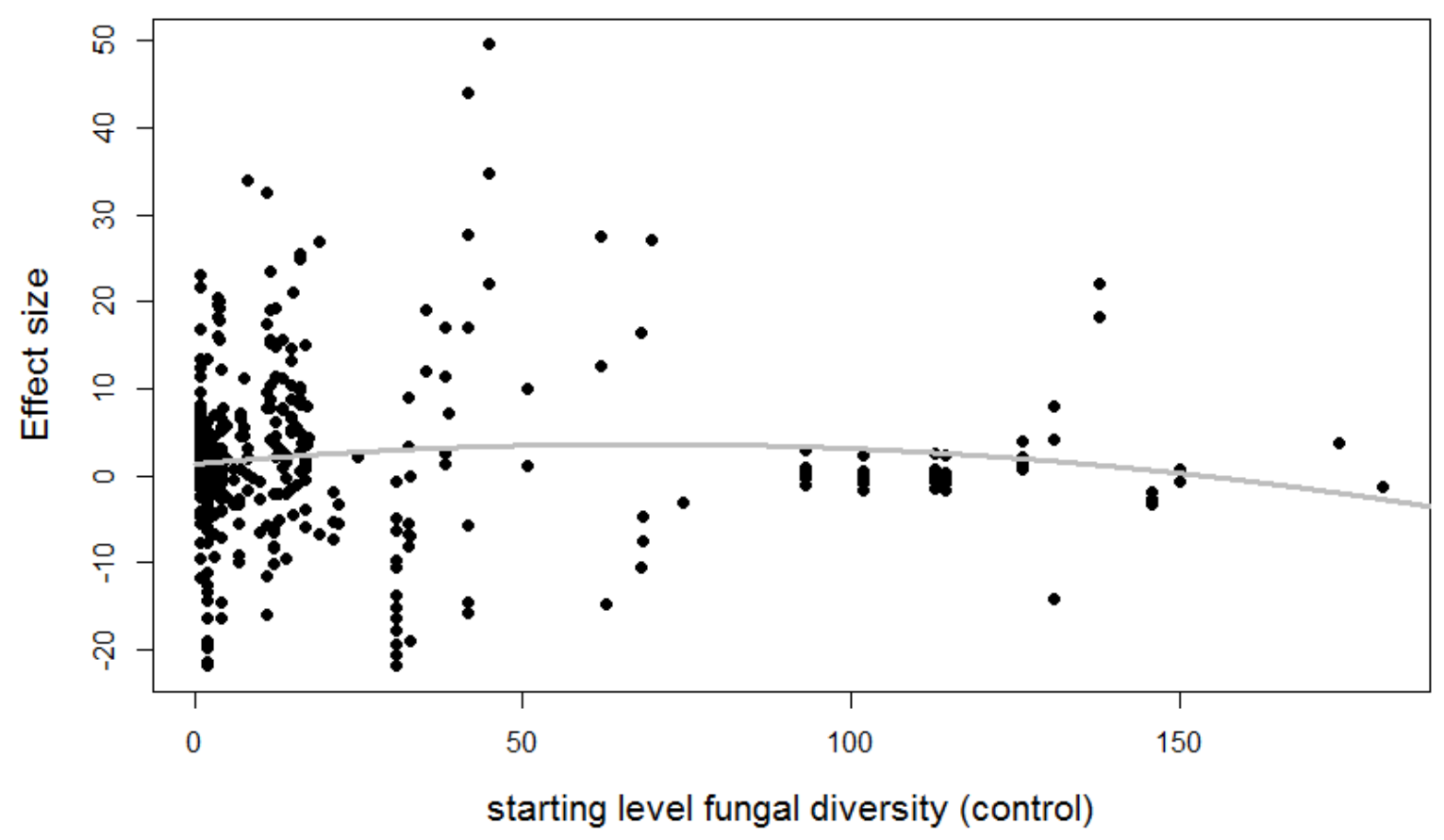

Figure 2: Relationship between effect size (D) and the starting level of fungal diversity within each comparison. Grey line is predicted model based on quadratic relationship $(p=0.27)$

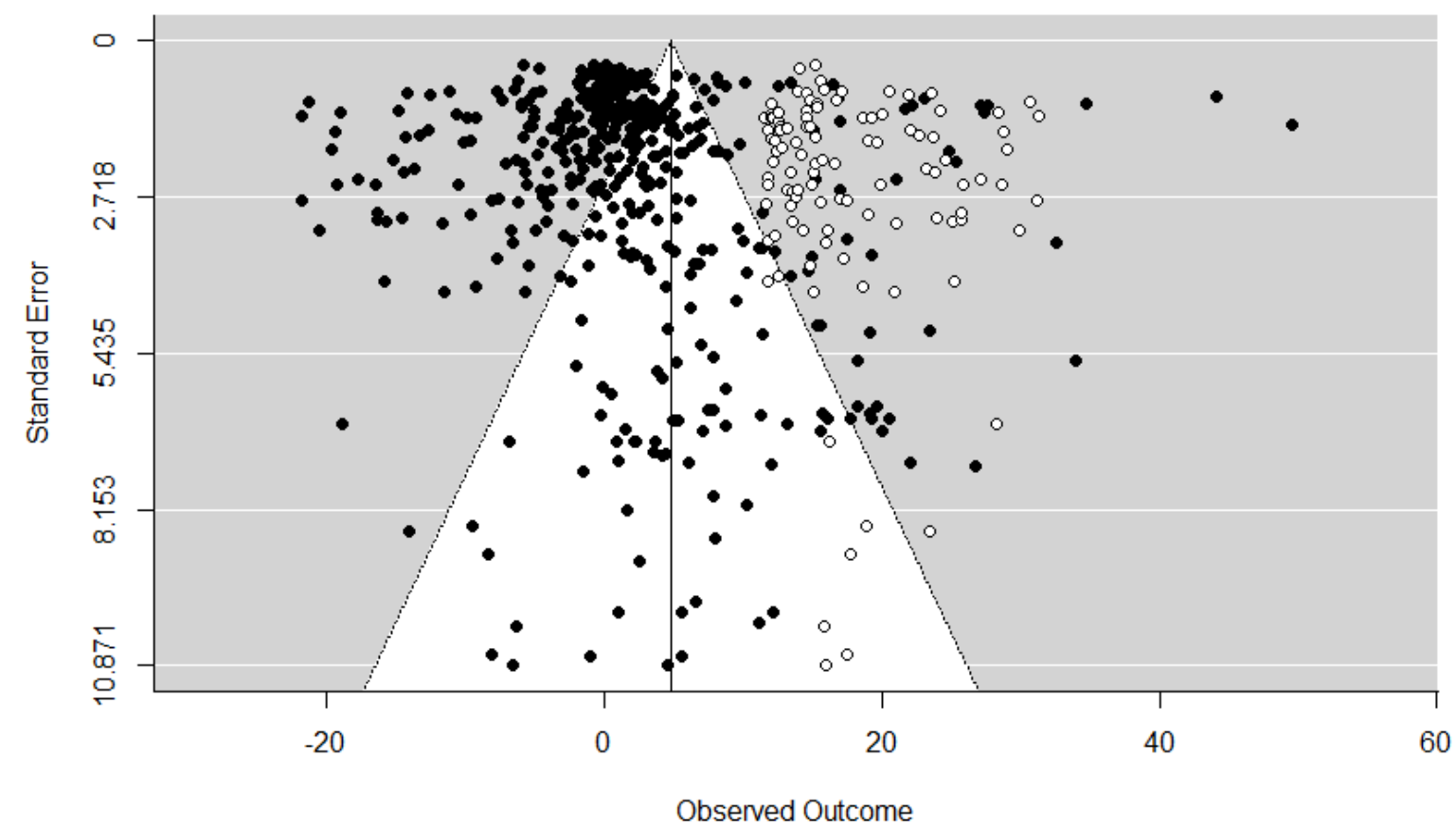

Figure 3: Estimate of publication bias (funnelplot): Individual diversity effect sizes are presented on the $x$-axis together with the average (black line) and the standard error of the individual effects is presented on the $y$-axis. Black dots represent individual measurements and white dots indicate possible missing measurements as the distribution of these measurements is expected to be symmetric around the average of all studies.

Plant quality

Correlation analysis revealed a significant negative relationship between the $\mathrm{C}: \mathrm{N}$ ratio of plant residues and diversity effect size $(r=-0.033 \pm 0.016, R=-0.11, p=0.034$, Figure 4$)$, supporting hypothesis 3 . The 
$\mathrm{C}: \mathrm{N}$ ratio of the plant material was based on an estimate from the TRY-database. For some plant species, however, this data was not available in the database.

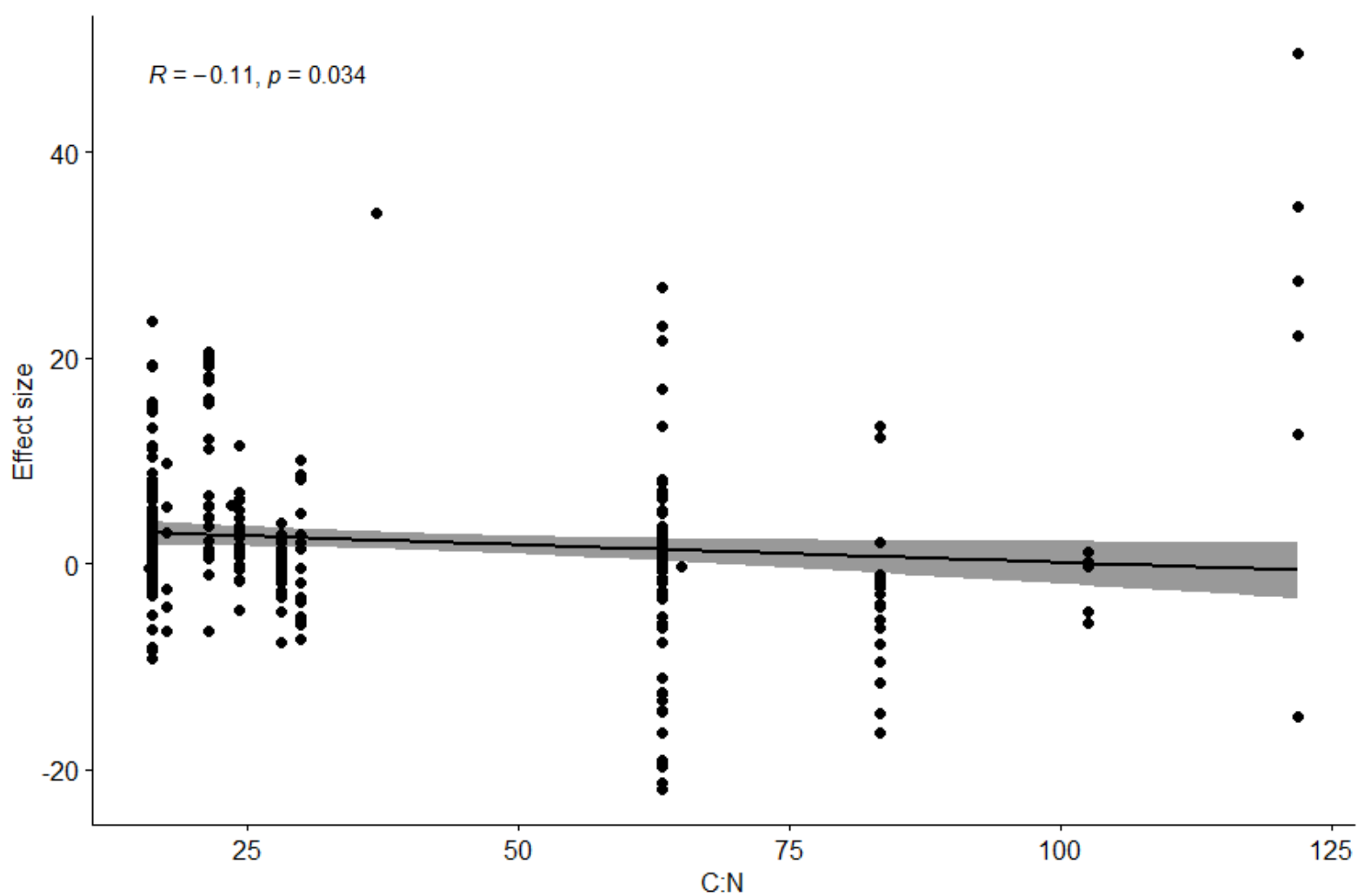

Figure 4: Correlation of estimated C:N ratio of plant material with individual diversity effect size $\mathrm{D}$

\section{$\underline{\text { Time effect }}$}

To study if time of harvest had an influence on the diversity effect size, the most used plant species was selected to compare different experiments. Alnus glutinosa was used in 7 manipulated experiments and 6 field experiments. These experiments were analyzed separately as laboratory conditions are not comparable with field conditions. For both types of experiments the time after which \% mass loss was measured did not have a significant negative effect on the individual diversity effect sizes ( $p=0.65$ and $p=0.98$ for manipulated and field experiments respectively, Figure 5), rejecting hypothesis 4 . 

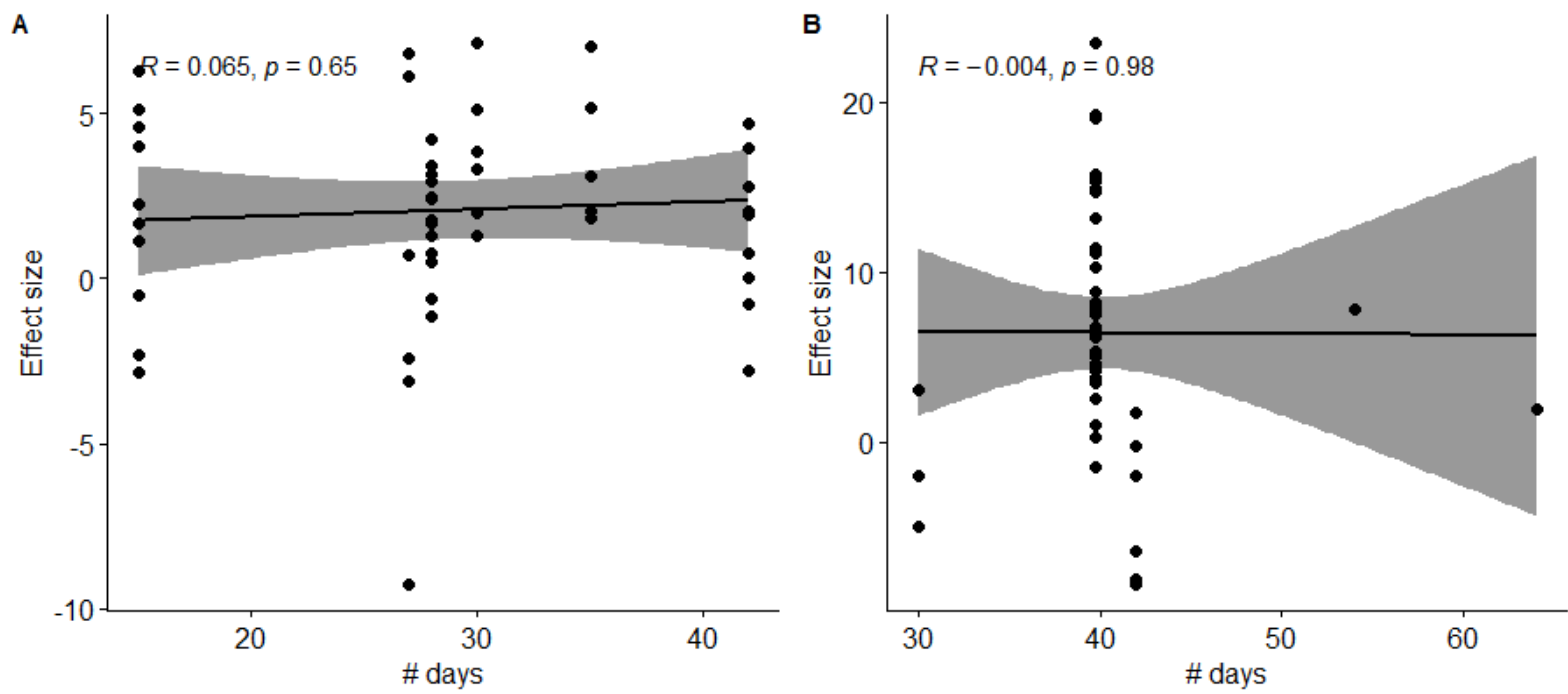

Figure 5: Correlation between time of mass loss measurements and diversity effect size $D$ for 13 studies with leaf litter of Alnus glutinosa D. A: manipulated experiments (7) ad B: field experiments (6)

\section{Discussion}

Soil biodiversity plays an important role in ecosystem functioning and nutrient cycling (Thiele-Bruhn et al., 2012; Wagg et al., 2014; Delgado-Baquerizo et al., 2016). As fungi play a prominent role in decomposition and carbon cycling (Creamer et al., 2016), the relationship with fungal diversity warrants special attention. Surprisingly, fungal diversity and decomposition are both well studied, but an overall analysis of their relationship has not been addressed. The current meta-analysis examined this both for controlled differences of diversity in experimental settings and for spontaneous assembly differences of diversity in field studies.

In this meta-analysis, we did find an overall positive effect of fungal diversity on decomposition $(D=$ $1.57 \pm 0.41, p<0.001$, Figure 1 ), as stated in hypothesis 1 . A positive effect of diversity in manipulated experiments was found when incubations with one fungal species were compared with incubations of two or more fungal species. Comparisons of higher initial richness (at least two fungal species as "control") with multispecies communities did not show such an effect, supporting the expected redundancy effect (hypothesis 2). However, studies of decomposition of naturally colonized substrates in field sites indicate an overall positive relationship between fungal diversity and decomposition regardless of the lowest diversity levels, thereby rejecting hypothesis 2 . These differences between manipulated experiments and natural ecosystems show a possible discrepancy in the representativeness of manipulated experiments for field situations as stated in hypothesis 5 . This can be explained in four ways as already discussed by Fukasawa and Matsukura (2021).

First, the fungal diversity levels used to determine the effect of increasing diversity levels on decomposition in experimental settings are the initial levels constructed by the researcher. Competitive exclusion may have leveled off the initial diversity differences in manipulated experiments. For example, Toljander et al. (2006) showed that only one or two species existed on decaying wood blocks after 6 months of incubation even though the highest inoculation diversity started with 16 species. Unfortunately, most studies did not take this species loss into account and used the initially inoculated numbers of species to calculate diversity effects on the decomposition as determined at the end of the incubation. This can result in a bias of studies reporting no significant effect of diversity on decomposition as shown in Figure 3. Both competitive interactions leading to a reduction in species and interactions in the remaining species-poor decomposer communities will 
bioRxiv preprint doi: https://doi.org/10.1101/2021.09.29.462096; this version posted September 29, 2021. The copyright holder for this preprint (which was not certified by peer review) is the author/funder. All rights reserved. No reuse allowed without permission.

greatly determine the effect on decomposition (Hiscox et al., 2015; Hiscox, O'Leary and Boddy, 2018). In field studies, fungal community composition and decomposition (weight loss) are determined at the same time. Hence, different from artificially manipulated diversity experiments, the relationship between decomposition and fungal diversity in field experiments is not based on the initial, but rather on the final fungal diversity. Therefore, the lack of effect of differences in initial species richness on decomposition in artificially assembled fungal communities cannot be considered as an appropriate test for diversity effects when final richness levels have not been included. Furthermore, in manipulated experiments, a random assembly of fungal species is used as inoculation while in field experiments succession and colonization are not random and can be selected by forces based on functioning, stimulating co-occurrence (Palmer, Stanton and Young, 2003; Dickie et al., 2012; van der Wal et al., 2013).

Second, the amount of detected species in field experiments is larger than the amount of used species in laboratory conditions (Grossart et al., 2019; Fukasawa and Matsukura, 2021). Only one experiment in this meta-analysis used dilution-to-extinction (Wagg et al., 2014) as a method to reduce diversity in laboratory conditions. Yet, this method might be more representative for differences in diversity levels in field situations as dilutions are made from naturally assembled fungal communities.

Third, differences in homogeneity and quality of the plant material within manipulated and field experiments can lead to differences in decomposition. In manipulated experiments, the plant material needs to be sterile before fungal communities can be inoculated. These pre-treatments do change the quality of the plant material. Comparisons between partly and fully sterilized material as a method to dilute fungal diversity is therefore not suitable to estimate diversity effects as reported previously (Valentín et al., 2014; Muszynski et al., 2021). Furthermore, homogenization of the material in laboratory conditions may reduce substrate complexity compared to field conditions. Increasing complexity of the environment and substrate can lead to reduced exclusion during competition and, therefore, lead to co-existence (Lee et al., 2019; Chan et al., 2021). Even in field situations, reduced resource complexity can lead to reduced diversity of fungal communities (Baessler et al., 2014).

Fourth, higher environmental heterogeneity in field experiments as compared to controlled incubation conditions may lead to differences in the relationship between fungal diversity and decomposition. Environmental heterogeneity can lead to increased possibilities for co-existence of fungal species (Bradford et al., 2014). Fungal species have specific ranges of abiotic stress tolerance (niche width) (Maynard et al., 2019). Therefore, spatial and temporal fluctuations in environmental conditions can facilitate species coexistence which can coincide with increased decomposition (Toljander et al., 2006). In this meta-analysis we included both aquatic and terrestrial ecosystems. Even though aquatic and terrestrial ecosystems are different, fungi fulfill an important role as decomposers of terrestrial plant material in both environments. In aquatic ecosystems, an important source of terrestrial plant material consists of fallen leaves and more than $50 \%$ of the organic matter in lakes has a terrestrial origin (Wilkinson, Pace and Cole, 2013). Fungal diversity in streams and lakes is simpler compared to terrestrial systems as a possible consequence of reduced environmental fluctuations in temperature and water availability in aquatic ecosystems (Bärlocher and Boddy, 2016; Grossart et al., 2019). Even though the presence of these differences, fungal functioning and interactions play similar roles in relationship to the degradation of plant material. However, a limited amount of studies was found that studied decomposition of plant litter in terrestrial ecosystems (4 studies) compared to aquatic ecosystems (28 studies). This bias hampers comparison of both ecosystems. A similar problem accounts for wood decomposition as well. Wood decomposition in aquatic ecosystems is rarely studied even though not only leaf litter but also twigs, branches and even trunks fall into streams as organic matter input (Allan and Castillo, 2007). This limited attention for aquatic wood decomposition is probably due to the assumed very slow decomposition of submerged wood, which has recently been questioned (Ferrer et al., 2020). More experimental studies analyzing fungal diversity within decomposing plant material in a diverse set of ecosystems is needed to be able to make better predictions. In addition, by using knowledge from decomposition models that include microbial 
parameters, it will be possible to better estimate decomposition rates under a changing climate and in different land use types. Until now, only a few models have been developed including microbial traits (Treseder et al., 2011; Allison, 2012; Sainte-Marie et al., 2021). Our results show that fungal biomass on its own is not enough and fungal diversity should be included in models to better estimate and understand ecosystem functioning. For example, in a modeling approach by Bastida et al. (2021) an estimate was made of both microbial diversity and biomass worldwide.

Apart from tested differences in the fungal diversity-decomposition relationship between manipulated and field experiments, we evaluated if plant quality influenced the fungal diversity effect on decomposition. We found a negative relationship between C:N ratio and the effect size supporting hypothesis 3 . In the current analysis, it was not possible to quantify the effect of the quality of the plant material in more detail as this information was lacking. Only one out of 40 papers measured C:N ratio. To overcome this problem, we extracted C: $N$ data from the TRY-database (Kattge et al., 2020). However, this is an estimation and an average of known measurements, but may not accurately reflect the wood and litter quality used in the experiments. Yet, we did find a negative effect of C:N ratio on the calculated diversity effect sizes $(r=-0.033 \pm 0.016, R=-0.11, p=0.034$, Figure 4$)$. This suggests that lower plant quality can lead to a reduction of positive effects of fungal diversity on decomposition. Antagonistic forces, such as the production of secondary metabolites and modification of the environment (e.g. reducing $\mathrm{pH}$ ) to protect occupied space and nutrient sources by the fungal species (Hiscox and Boddy, 2016; Baldrian, 2017), can result in reduced diversity. For example, Baldrian et al. (2016) showed that individual wood logs were dominated by one or a few fungal species. Other information about the quality of the plant material, like lignin concentration, can give more insight in the relationship between the plant quality and decomposition (Hall et al., 2020). In the selected studies, only a limited amount of data was available for such plant traits. Therefore, other traits related to quality of litter and wood used for the decomposition studies were not included in the analyses.

To test if incubation time had an effect on diversity-decomposition relationships (hypothesis 4), we selected only studies that used Alnus glutinosa leaf litter. Within these studies, the differences between harvesting time periods were minimal (ranging from 15 days to 42 days in laboratory conditions and 30 to 64 days in field conditions). This might be the reason for not finding a significant effect and rejecting hypothesis 4 . To be able to understand the effect of time on fungal diversitydecomposition relationships, it is better to analyze decomposition at different time points within the same study to account for environmental differences. For example, Fernandes et al. (2009) measured decomposition over time, but this study could not be used since the temperature treatments created a diversity effect (exclusion reason 1: contrasting environment or plant material).

In conclusion, fungal diversity is an important parameter to take into account to estimate and understand decomposition. Experimental studies examining fungal diversity effects on ecosystem functioning do not represent natural environments, leading to the need of doing more field experiments to determine fungal diversity-functioning relationships.

\section{References}

Allan, J. David. and Castillo, M. M. (2007) Stream ecology : structure and function of running waters. 2nd ed. Dordrecht: Springer. Available at: http://site.ebrary.com/id/10230521.

Allison, S. D. (2012) 'A trait-based approach for modelling microbial litter decomposition', Ecol Lett, 15(9), pp. 1058-70. doi: 10.1111/j.1461-0248.2012.01807.x.

Andrade, R., Pascoal, C. and Cássio, F. (2016) 'Effects of inter and intraspecific diversity and genetic divergence of aquatic fungal communities on leaf litter decomposition-a microcosm experiment', FEMS Microbiology Ecology, 92(7), pp. fiw102-fiw102. doi: 10.1093/femsec/fiw102.

Baerlocher, F. (2005) 'Freshwater Fungal Communities', in The Fungal Community: Its Organization and Role in the Ecosystem, pp. 39-59. doi: 10.1201/9781420027891.ch3. 
bioRxiv preprint doi: https://doi.org/10.1101/2021.09.29.462096; this version posted September 29, 2021. The copyright holder for this preprint (which was not certified by peer review) is the author/funder. All rights reserved. No reuse allowed without permission.

Baessler, C. et al. (2014) 'Near-to-nature logging influences fungal community assembly processes in a temperate forest', JOURNAL OF APPLIED ECOLOGY. 111 RIVER ST, HOBOKEN 07030-5774, NJ USA: WILEY. doi: 10.1111/1365-2664.12267.

Baldrian, P. et al. (2016) 'Fungi associated with decomposing deadwood in a natural beech-dominated forest', Fungal Ecology, 23, pp. 109-122. doi: 10.1016/j.funeco.2016.07.001.

Baldrian, P. (2017) 'Forest microbiome: diversity, complexity and dynamics', FEMS Microbiology Reviews, 41(2), pp. 109-130. doi: 10.1093/femsre/fuw040.

Bärlocher, F. and Boddy, L. (2016) 'Aquatic fungal ecology - How does it differ from terrestrial?', Aquatic Fungi, 19, pp. 5-13. doi: 10.1016/j.funeco.2015.09.001.

Bärlocher, F. and Corkum, M. (2003) 'Nutrient enrichment overwhelms diversity effects in leaf decomposition by stream fungi', Oikos, 101(2), pp. 247-252. doi: 10.1034/j.1600-0706.2003.12372.x.

BÄRLOCHER, F. and GRAÇA, M. A. S. (2002) 'Exotic riparian vegetation lowers fungal diversity but not leaf decomposition in Portuguese streams', Freshwater Biology, 47(6), pp. 1123-1135. doi: 10.1046/j.13652427.2002.00836.x.

Barros, D. et al. (2016) 'Ethanol and phenanthrene increase the biomass of fungal assemblages and decrease plant litter decomposition in streams', Science of The Total Environment, 565, pp. 489-495. doi: http://dx.doi.org/10.1016/j.scitotenv.2016.04.190.

Bastida, F. et al. (2021) 'Soil microbial diversity-biomass relationships are driven by soil carbon content across global biomes', The ISME Journal. doi: 10.1038/s41396-021-00906-0.

Bradford, M. A. et al. (2014) 'Climate fails to predict wood decomposition at regional scales', Nature Climate Change, 4(7), pp. 625-630. doi: 10.1038/nclimate2251.

Chan, J. Y. et al. (2021) 'Complex Environments Alter Competitive Dynamics in Fungi', EcoEvoRxiv, January 2021. doi: 10.32942/osf.io/pf3kq.

Coleman, D. C. and Whitman, W. B. (2005) 'Linking species richness, biodiversity and ecosystem function in soil systems', Pedobiologia, 49(6), pp. 479-497. doi: 10.1016/j.pedobi.2005.05.006.

COSTANTINI, M. L. and ROSSI, L. (2010) 'Species diversity and decomposition in laboratory aquatic systems: the role of species interactions', Freshwater Biology, 55(11), pp. 2281-2295. doi: 10.1111/j.13652427.2010.02433.x.

Creamer, R. E. et al. (2016) 'Ecological network analysis reveals the inter-connection between soil biodiversity and ecosystem function as affected by land use across Europe', Soil biodiversity and ecosystem functions across Europe: A transect covering variations in bio-geographical zones, land use and soil properties, 97, pp. 112-124. doi: 10.1016/j.apsoil.2015.08.006.

Dang, C. K., Chauvet, E. and Gessner, M. O. (2005) 'Magnitude and variability of process rates in fungal diversity-litter decomposition relationships', Ecology Letters, 8(11), pp. 1129-1137. doi: 10.1111/j.14610248.2005.00815.x.

Deacon, L. J. et al. (2006) 'Diversity and function of decomposer fungi from a grassland soil', Soil Biology and Biochemistry, 38(1), pp. 7-20. doi: 10.1016/j.soilbio.2005.04.013.

Delgado-Baquerizo, M. et al. (2016) 'Microbial diversity drives multifunctionality in terrestrial ecosystems', Nature Communications, 7, p. 8. doi: 10.1038/ncomms10541.

Delgado-Baquerizo, M. et al. (2017) 'Microbial richness and composition independently drive soil multifunctionality', Functional Ecology, 31(12), pp. 2330-2343. doi: 10.1111/1365-2435.12924.

Dickie, I. A. et al. (2012) 'Do assembly history effects attenuate from species to ecosystem properties? A field test with wood-inhabiting fungi', Ecology Letters, 15(2), pp. 133-141. doi: 10.1111/j.14610248.2011.01722.x.

Duarte, S. et al. (2006) 'Aquatic hyphomycete diversity and identity affect leaf litter decomposition in microcosms', Oecologia, 147(4), pp. 658-666. doi: 10.1007/s00442-005-0300-4.

Duarte, S. et al. (2010) 'Assessing the dynamic of microbial communities during leaf decomposition in a loworder stream by microscopic and molecular techniques', Microbiological Research, 165(5), pp. 351-362. doi: 10.1016/j.micres.2009.06.002.

Encalada, A. et al. (2010) 'Riparian land use and the relationship between the benthos and litter decomposition in tropical montane streams', Freshwater Biology, 55, pp. 1719-1733. doi: 10.1111/j.13652427.2010.02406.x.

Fernandes, I. et al. (2009) 'Responses of Aquatic Fungal Communities on Leaf Litter to Temperature-Change Events', International Review of Hydrobiology, 94(4), pp. 410-418. doi: 10.1002/iroh.200811163.

Fernandes, I., Pascoal, C. and Cássio, F. (2011) 'Intraspecific traits change biodiversity effects on ecosystem functioning under metal stress', Oecologia, 166(4), pp. 1019-1028. doi: 10.1007/s00442-011-1930-3. 
bioRxiv preprint doi: https://doi.org/10.1101/2021.09.29.462096; this version posted September 29, 2021. The copyright holder for this preprint (which was not certified by peer review) is the author/funder. All rights reserved. No reuse allowed without permission.

Ferreira, V. et al. (2006) 'Eucalyptus plantations affect fungal communities associated with leaf-litter decomposition in Iberian streams', Archiv Fur Hydrobiologie, 166(4), pp. 467-490. doi: 10.1127/00039136/2006/0166-0467.

Ferrer, A. et al. (2020) 'Contribution of fungal and invertebrate communities to wood decay in tropical terrestrial and aquatic habitats', Ecology, 101. doi: 10.1002/ecy.3097.

Fukasawa, Y. and Matsukura, K. (2021) 'Decay stages of wood and associated fungal communities characterise diversity-decomposition relationships', Scientific Reports, 11(1), p. 8972. doi: 10.1038/s41598-021-88580-2.

Geraldes, P., Pascoal, C. and Cássio, F. (2012) 'Effects of increased temperature and aquatic fungal diversity on litter decomposition', Fungal Ecology, 5(6), pp. 734-740. doi: http://dx.doi.org/10.1016/j.funeco.2012.05.007.

Gessner, M. O. et al. (2010) 'Diversity meets decomposition', Trends in Ecology \& Evolution, 25(6), pp. 372-380. doi: http://dx.doi.org/10.1016/j.tree.2010.01.010.

Gonçalves, A. L., Graça, M. A. S. and Canhoto, C. (2015) 'Is diversity a buffer against environmental temperature fluctuations? - A decomposition experiment with aquatic fungi', Fungal Ecology, 17, pp. 96-102. doi: 10.1016/j.funeco.2015.05.013.

Grossart, H.-P. et al. (2019) 'Fungi in aquatic ecosystems', Nature Reviews Microbiology, 17(6), pp. 339-354. doi: 10.1038/s41579-019-0175-8.

Hall, S. J. et al. (2020) 'Lignin lags, leads, or limits the decomposition of litter and soil organic carbon', ECOLOGY. 111 RIVER ST, HOBOKEN 07030-5774, NJ USA: WILEY. doi: 10.1002/ecy.3113.

Harrop, B. L., Marks, J. C. and Watwood, M. E. (2009) 'Early bacterial and fungal colonization of leaf litter in Fossil Creek, Arizona', Journal of the North American Benthological Society, 28(2), pp. 383-396. doi: 10.1899/08-068.1.

Hättenschwiler, S., Fromin, N. and Barantal, S. (2011) 'Functional diversity of terrestrial microbial decomposers and their substrates', Biodiversity in face of human activities / La biodiversite face aux activites humaines, 334(5), pp. 393-402. doi: 10.1016/j.crvi.2011.03.001.

Hiscox, J. et al. (2015) 'Antagonistic fungal interactions influence carbon dioxide evolution from decomposing wood', Fungal Ecology, 14, pp. 24-32. doi: 10.1016/j.funeco.2014.11.001.

Hiscox, J. et al. (2016) 'Effects of pre-colonisation and temperature on interspecific fungal interactions in wood', Fungal Ecology, 21, pp. 32-42. doi: 10.1016/j.funeco.2016.01.011.

Hiscox, J. and Boddy, L. (2016) 'Fungal Ecology: Principles and Mechanisms of Colonization and Competition by Saprotrophic Fungi', Microbiology Spectrum, 4, p. 1. doi: 10.1128/microbiolspec.FUNK-0019-2016.

Hiscox, J., O'Leary, J. and Boddy, L. (2018) 'Fungus wars: basidiomycete battles in wood decay', Leading women in fungal biology, 89, pp. 117-124. doi: 10.1016/j.simyco.2018.02.003.

Hoppe, B. et al. (2016) 'Linking molecular deadwood-inhabiting fungal diversity and community dynamics to ecosystem functions and processes in Central European forests', Fungal Diversity, 77(1), pp. 367-379. doi: 10.1007/s13225-015-0341-x.

Hyde, K. D. et al. (2007) 'Diversity of saprobic microfungi', Biodiversity and Conservation, 16(1), pp. 7-35. doi: 10.1007/s10531-006-9119-5.

Jabiol, J. et al. (2013) 'Trophic complexity enhances ecosystem functioning in an aquatic detritus-based model system', Journal of Animal Ecology, 82(5), pp. 1042-1051. doi: 10.1111/1365-2656.12079.

Kattge, J. et al. (2020) 'TRY plant trait database - enhanced coverage and open access', Global Change Biology, 26(1), pp. 119-188. doi: 10.1111/gcb.14904.

Kivlin, S. N. and Treseder, K. K. (2015) 'Initial Phylogenetic Relatedness of Saprotrophic Fungal Communities Affects Subsequent Litter Decomposition Rates', Microbial Ecology, 69(4), pp. 748-757. doi: 10.1007/s00248-014-0509-z.

Krevs, A. et al. (2017) 'Microbial colonization and decomposition of invasive and native leaf litter in the littoral zone of lakes of different trophic state', LIMNOLOGICA. HACKERBRUCKE 6, 80335 MUNICH, GERMANY: ELSEVIER GMBH. doi: 10.1016/j.limno.2017.08.002.

Kubartová, A., Ottosson, E. and Stenlid, J. (2015) 'Linking fungal communities to wood density loss after 12 years of log decay', FEMS Microbiology Ecology, 91(fiv032). doi: 10.1093/femsec/fiv032.

Lecerf, A. and Chauvet, E. (2008) 'Diversity and functions of leaf-decaying fungi in human-altered streams', Freshwater Biology, 53(8), pp. 1658-1672. doi: 10.1111/j.1365-2427.2008.01986.x.

Lecerf, A. and Richardson, J. S. (2010) 'Biodiversity-ecosystem function research: Insights gained from streams', River Research and Applications, 26(1), pp. 45-54. doi: 10.1002/rra.1286.

Lee, M. R. et al. (2019) 'Good neighbors aplenty: fungal endophytes rarely exhibit competitive exclusion patterns across a span of woody habitats', ECOLOGY. 111 RIVER ST, HOBOKEN 07030-5774, NJ USA: WILEY. doi: 10.1002/ecy.2790. 
bioRxiv preprint doi: https://doi.org/10.1101/2021.09.29.462096; this version posted September 29, 2021. The copyright holder for this preprint (which was not certified by peer review) is the author/funder. All rights reserved. No reuse allowed without permission.

Maamri, A. et al. (2001) 'Fungal and Bacterial Colonisation of Salix pedicellataLeaves Decaying in Permanent and Intermittent Streams in Eastern Morocco', International Review of Hydrobiology, 86(3), pp. 337-348. doi: 10.1002/1522-2632(200106)86:3<337::AID-IROH337>3.0.CO;2-N.

Makowski, D., Piraux, F. and Brun, F. (2019) From Experimental Network to Meta-analysis: Methods and Applications with $R$ for Agronomic and Environmental Sciences. doi: 10.1007/978-94-024-1696-1.

Maynard, D. S. et al. (2019) 'Consistent trade-offs in fungal trait expression across broad spatial scales', Nature Microbiology, 4(5), pp. 846-853. doi: 10.1038/s41564-019-0361-5.

Mesquita, A., Pascoal, C. and Cassio, F. (2007) 'Assessing effects of eutrophication in streams based on breakdown of eucalypt leaves', Fundamental and Applied Limnology, 168(3), pp. 221-230. doi: 10.1127/1863-9135/2007/0168-0221.

Mester, T., Varela, E. and Tien, M. (2004) 'Wood Degradation by Brown-Rot and White-Rot Fungi', in Kück, U. (ed.) Genetics and Biotechnology. Berlin, Heidelberg: Springer Berlin Heidelberg, pp. 355-368. doi: 10.1007/978-3-662-07426-8_17.

Miura, T. et al. (2013) 'No tillage and bagasse mulching alter fungal biomass and community structure during decomposition of sugarcane leaf litter in Lampung Province, Sumatra, Indonesia', Soil Biology and Biochemistry, 58, pp. 27-35. doi: http://dx.doi.org/10.1016/j.soilbio.2012.10.042.

Miura, T. et al. (2015) 'Diversity of Fungi on Decomposing Leaf Litter in a Sugarcane Plantation and Their Response to Tillage Practice and Bagasse Mulching: Implications for Management Effects on Litter Decomposition', Microbial Ecology, 70(3), pp. 646-658. doi: 10.1007/s00248-015-0620-9.

Muszynski, S. et al. (2021) 'Fungal and Bacterial Diversity Patterns of Two Diversity Levels Retrieved From a Late Decaying Fagus sylvatica Under Two Temperature Regimes', Frontiers in Microbiology, 11, p. 3168. doi: 10.3389/fmicb.2020.548793.

Palmer, T. M., Stanton, M. L. and Young, T. P. (2003) 'Competition and Coexistence: Exploring Mechanisms That Restrict and Maintain Diversity within Mutualist Guilds.', The American Naturalist, 162(S4), pp. S63-S79. doi: $10.1086 / 378682$.

Pascoal, C. et al. (2010) 'Realized Fungal Diversity Increases Functional Stability of Leaf Litter Decomposition Under Zinc Stress', Microbial Ecology, 59(1), pp. 84-93. doi: 10.1007/s00248-009-9567-z.

Pascoal, C., Cassio, F. and Marvanová, L. (2005) 'Anthropogenic stress may affect aquatic hyphomycete diversity more than leaf decomposition in a low-order stream', Archiv für Hydrobiologie, 162, pp. 481-496. doi: 10.1127/0003-9136/2005/0162-0481.

Pérez, J., Descals, E. and Pozo, J. (2012) 'Aquatic Hyphomycete Communities Associated with Decomposing Alder Leaf Litter in Reference Headwater Streams of the Basque Country (northern Spain)', Microbial Ecology, 64(2), pp. 279-290. doi: 10.1007/s00248-012-0022-1.

Purahong, W. et al. (2017) 'Characterization of Unexplored Deadwood Mycobiome in Highly Diverse Subtropical Forests Using Culture-independent Molecular Technique', FRONTIERS IN MICROBIOLOGY. AVENUE DU TRIBUNAL FEDERAL 34, LAUSANNE, CH-1015, SWITZERLAND: FRONTIERS MEDIA SA. doi: 10.3389/fmicb.2017.00574.

Raviraja, N. S., Nikolcheva, L. G. and Baerlocher, F. (2006) 'Fungal growth and leaf decomposition are affected by amount and type of inoculum and by external nutrients', Sydowia -Horn-, 58, pp. 91-104.

Rincon, J. and Santelloco, R. (2009) 'Aquatic fungi associated with decomposing Ficus sp. leaf litter in a neotropical stream', Journal of the North American Benthological Society, 28(2), pp. 416-425. doi: 10.1899/07-084.1.

Sainte-Marie, J. et al. (2021) 'C-STABILITY an innovative modeling framework to leverage the continuous representation of organic matter', NATURE COMMUNICATIONS. HEIDELBERGER PLATZ 3, BERLIN, 14197, GERMANY: NATURE RESEARCH. doi: 10.1038/s41467-021-21079-6.

Simon, K. S., Simon, M. A. and Benfield, E. F. (2009) 'Variation in ecosystem function in Appalachian streams along an acidity gradient', Ecological Applications, 19(5), pp. 1147-1160. doi: 10.1890/08-0571.1.

Sterne, J. A. C. and Egger, M. (2001) 'Funnel plots for detecting bias in meta-analysis: Guidelines on choice of axis', Journal of Clinical Epidemiology, 54(10), pp. 1046-1055. doi: 10.1016/S0895-4356(01)00377-8.

Sudheep, N. M. and Sridhar, K. R. (2013) 'Colonization and diversity of aquatic hyphomycetes in relation to decomposition of submerged leaf litter in River Kali (Western Ghats, India)', Mycosphere, 4(3), pp. 456-476. doi: $10.5943 /$ mycosphere/4/3/3.

Thiele-Bruhn, S. et al. (2012) 'Linking soil biodiversity and agricultural soil management', Current Opinion in Environmental Sustainability, 4(5), pp. 523-528. doi: 10.1016/j.cosust.2012.06.004.

Tiunov, A. V. and Scheu, S. (2005) 'Facilitative interactions rather than resource partitioning drive diversityfunctioning relationships in laboratory fungal communities', Ecology Letters, 8(6), pp. 618-625. doi: 10.1111/j.1461-0248.2005.00757.x. 
bioRxiv preprint doi: https://doi.org/10.1101/2021.09.29.462096; this version posted September 29, 2021. The copyright holder for this preprint (which was not certified by peer review) is the author/funder. All rights reserved. No reuse allowed without permission.

Toljander, Y. K. et al. (2006) 'Environmental fluctuations facilitate species co-existence and increase decomposition in communities of wood decay fungi', Oecologia, 148(4), pp. 625-631. doi: 10.1007/s00442006-0406-3.

Tolkkinen, M. et al. (2013) 'Decomposer communities in human-impacted streams: species dominance rather than richness affects leaf decomposition', Journal of Applied Ecology, 50(5), pp. 1142-1151. doi: 10.1111/1365-2664.12138.

Tolkkinen, Mikko et al. (2015) 'Human disturbance increases functional but not structural variability of stream fungal communities', Functional Ecology, 29(12), pp. 1569-1577. doi: 10.1111/1365-2435.12469.

Tolkkinen, M. et al. (2015) 'Multi-stressor impacts on fungal diversity and ecosystem functions in streams: natural vs. anthropogenic stress', Ecology, 96(3), pp. 672-683. doi: 10.1890/14-0743.1.

Treseder, K. K. et al. (2011) 'Integrating microbial ecology into ecosystem models: challenges and priorities', Biogeochemistry, 109(1-3), pp. 7-18. doi: 10.1007/s10533-011-9636-5.

Valentín, L. et al. (2014) 'Loss of diversity in wood-inhabiting fungal communities affects decomposition activity in Norway spruce wood', Frontiers in Microbiology, 5. doi: 10.3389/fmicb.2014.00230.

Venugopal, P. et al. (2017) 'Assemblage composition of fungal wood-decay species has a major influence on how climate and wood quality modify decomposition', FEMS MICROBIOLOGY ECOLOGY. GREAT CLARENDON ST, OXFORD OX2 6DP, ENGLAND: OXFORD UNIV PRESS. doi: 10.1093/femsec/fix002.

Viechtbauer, W. (2010) 'Conducting Meta-Analyses in R with the metafor Package', Journal of Statistical Software, Articles, 36(3), pp. 1-48. doi: 10.18637/jss.v036.i03.

Wagg, C. et al. (2014) 'Soil biodiversity and soil community composition determine ecosystem multifunctionality', Proceedings of the National Academy of Sciences of the United States of America, 111(14), pp. 5266-5270. doi: 10.1073/pnas.1320054111.

van der Wal, A. et al. (2013) 'A thready affair: linking fungal diversity and community dynamics to terrestrial decomposition processes', FEMS Microbiology Reviews, 37(4), pp. 477-494. doi: 10.1111/1574-6976.12001.

van der Wal, A. et al. (2016) 'Patterns of natural fungal community assembly during initial decay of coniferous and broadleaf tree logs', Ecosphere, 7. doi: 10.1002/ecs2.1393.

van der Wal, A., Ottoson, E. and De Boer, W. (2015) 'Neglected role of fungal community composition in explaining variation in wood decay rates', Ecology, 96.

Wilkinson, G. M., Pace, M. L. and Cole, J. J. (2013) 'Terrestrial dominance of organic matter in north temperate lakes', Global Biogeochemical Cycles, 27(1), pp. 43-51. doi: 10.1029/2012GB004453.

Xiao, W. Y. et al. (2019) 'Multiple interactions between tree composition and diversity and microbial diversity underly litter decomposition', Geoderma, 341, pp. 161-171. doi: 10.1016/j.geoderma.2019.01.045. 